\title{
EL JARDÍN BOTÁNICO PRÍNCIPE DE LA PAZ DE SANLÚCAR DE BARRAMEDA: UNA INSTITUCIÓN ILUSTRADA AL SERVICIO DE LA PRODUCCIÓN AGRARIA Y FORESTAL
}

Antonio CABRAL CHAMORRO*

\author{
A Josefa de la Piedra, \\ Botánica sanluqueña.
}

\section{INTRODUCCIÓN}

Sin duda alguna, entre los méritos del Monarca Carlos III, estuvo el saberse morir a tiempo'. El "mejor" alcalde de Madrid dejó de existir en diciembre de 1788; seis meses después estallaba la Revolución Francesa; el pánico se apoderó de las clases dirigentes españolas y el gobierno de Floridablanca terminó con cualquier veleidad reformista hasta tiempos más tranquilos ${ }^{2}$.

El párrafo anterior no pretende restar mérito al empuje carolino, sino subrayar el esfuerzo y continuidad renovadora en la que se empeñó la dinastía borbónica ${ }^{3}$ y

* Profesor del I.B. Sta. Isabel de Hungría y componente del Grupo de Investigación en la Universidad de Cádiz.

1. La expresión no es original mía, se la escuché a J. Fontana en una conferencia en los salones de la Diputación gaditana en 1988. Con Fontana coincide C. Seco Serrano (1978 a, p. 18 y 1978 b) cuando sale en defensa de Godoy en los siguientes términos: "Políticamente, la inflexión que lleva desde la brillante plenitud carlostercerista al desastre de 1808, se debe a factores extemos de primera magnitud (nada menos que la Revolución y la era napoleónica) que hubiera determinado análogas consecuencias aunque el gobiemo paternal del buen rey Carlos III se hubiese prolongado hasta el siglo XIX".

2. R. Herr (1979), pp. 197-221; G. Anes )1969) y (1989); L. Domergue (1989); A.Elorza (1989) y A. Domínguez Ortiz (1989).

3. A. Mestre $(1976$, p. 18) va más allá y sitúa los orígenes de la Ilustración española en el último tercio del siglo XVII y escribe que "limitar los orígenes de la ilustración española a la actividad de cultural del padre Feijoo y a su adaptaciones de Les Mémories de Trévoux o Journal des savants es condenarse voluntariamente a no entender nada. En todo caso se podría entender la ilustración oficial, pero no la realidad intelectual ni las inquietudes de los hombres de letras". 
que tuvo uno de sus focos privilegiados (complejo científico tecnológico en palabra de M.A. Selles) en la provincia de Cádiz: fundación del Colegio de Cirugía $(1748)^{4}$, de las academias de Guardiamarinas (1717) e Ingenieros (1750) y el Observatorio de Marina (1755) 5 . Instituciones todas vinculadas al ámbito militar y que, al paso, nos informan acerca de una de las grandes preocupaciones de la nueva dinastía: restaurar el prestigio del Estado y de la monarquía que devolvieran a España su papel de gran potencia política y militar ${ }^{6}$.

Firmada la paz con Francia, recobrada la confianza por las clases dirigentes españolas y Godoy en el timón de Estado se abrió paso el último capítulo de la Ilustración española ${ }^{7}$.

Independientemente de lo controvertida de la imagen del Príncipe de la Paz alabado por unos y criticado por otros, de lo que no puede dudarse es la labor creativa y de apoyo que este brindó a diversas instituciones ${ }^{9} ; \mathrm{y}$, obra suya es en exclusiva el Jardín Botánico de Sanlúcar de Barrameda.

Mala suerte ha tenido entre los historiadores el Botánico sanluqueño. La fecha de su creación, 1805, no encaja con ningún centenario digno de conmemorarse. En primer lugar, al ser posterior a la vida y obra de Celestino Mutis, pasó desapercibido en el 250 aniversario del nacimiento del sabio, como prueban las 45 ponencias editadas del Simposium celebrado en Cádiz en $1982^{10}$ y, en segundo lugar, tampoco se benefició de la masiva producción historiográfica y editorial a que ha dado lugar el bicentenario del fallecimiento "bueno" Carlos III"1. De modo que para

4. D. Ferrer (1961).

5. La Academia y el Observatorio en, M.A. Selles (1988), (1988b) y (1991).

6. A. Lafuente (1985); M. Casado Arboniés (1991) y A. Lafuente y J.L. Peset (1988).

7. Véase el capítulo de la obra de R. Herr (1979, pp. 290-313), "Godoy y el resurgimiento de la Ilustración” y el mismo Godoy (1965, vol. I, p. 191): "¿quién me encontró jamás temeroso ni enemigo de las luces? lejos de adaptarlas, procuraba yo encenderlas y buscar su claridad precavidas sus explosiones. Las amé constantemente, y para no temerlas las hice aliada del Gobierno. En vez de perseguir, libertaba a los perseguidos".

8. Véase C. Seco Serrano (1978); A. Alfonso Bullón de Mendoza (1968). Finalmente, aunque a juicio de J. Aymes (1989, p. 19) las obras J. Chastenet (1963); H.R. Madol (1987), entre otras no pueden recomendarse "por no alimentan bastante la reflexión" he de reconocer que cayeron en mis manos.

9. Recordemos aquí, por lo que nos interesa el Seminario de Agricultura y Arte dirigido a los Párrocos (SAAP), editado en Madrid en 1797 y 1808 . Una defensa certera de Godoy en, C. Seco Serrano (1978a) y (1978b) y la mejor defensa el mismo M. Godoy (1965), vol. I, pp. 18-19, 190-244, 347-351, 369-378 y 401416 y vol. II, pp. 22-27,63-66, 124-126 y $133-157$.

10. Actas del Simposium CCL Aniversario del nacimiento de Josep Celestino Mutis, Diputación de Cádiz, Cádiz, 1986.

11. Véase por ejemplo, M. Selles, J.L. Peset y A. Fafuente (comps.) (1988) y Actas del Congreso Internacional sobre Carlos III y la llustración, Ministerio de Cultura, Madrid, 1989, 3 vols. Respecto al "furor conmemorativo" de algunos centenarios es necesario recordar, como lo ha hecho no hace mucho J. Fontana (1989) que "la historia ha sido usada tradicionalmente (y ahora también) para difundir los valores ideológicos que conviene al sistema establecido". No fue ninguna casualidad que un Real Decreto de fecha de 12 de diciembre de 1986 creara una comisión de 24 personas encargada de celebrar la conmemoración del bicentenario en la "forma debida", esto es, como ha señalado el Equipo Madrid (1988, pp. VII-VIII), 
encontrar algo escrito sobre el botánico sanluqueño habíamos de conformarnos con las páginas que ya dejara escritas F. Guillamas en $1858^{12}$, P. Barbadillo Delgado en $1942^{13}$ y el reciente y jugoso artículo publicado A.I. Bueno en $1985^{14}$.

La localización por mi parte de nuevos materiales me permiten relanzar modestamente el Botánico sanluqueño sobre el que hasta la fecha todo parecía dicho ${ }^{15}$.

\section{EL ORIGEN DEL BOTÁNICO "PRÍNCIPE DE LA PAZ"}

El origen del Botánico sanluqueño tenemos que enmarcarlo dentro de la política científica de los monarcas ilustrados españoles deI siglo XVIII y cuyo objetivo no es otro que el aumento de la producción agraria e industrial, la mejora de la salud pública y el mantenimiento del Imperio ${ }^{16}$. En realidad nada nuevo, pero ahora se trataba de hacerlo de un modo más racional y provechoso. Este contexto general, como primer paso, es útil pero conlleva el riesgo de disolver el Botánico sanluqueño en el rosario nacional de jardines de aclimatación de plantas exóticas y terapéuticos creados en el último tercio del siglo XVIII y que obedecen, de una u otra manera, a la labor institucional desarrollada desde el Real Jardín Botánico de Madrid por Casimiro Gómez Ortega ${ }^{17}$. Pero sobre todo no resuelve el hecho de por qué Sanlúcar y no por ejemplo la ciudad del Puerto de Santa María. Ambas ciudades gozan de idéntico clima y situación geográfica ideal junto a la cabecera del comercio indiano. Y lo que es todavía más sorprendente: en favor de El Puerto de Santa María jugaba el que esta ciudad fuera la elegida por el monarca Carlos IlI, años atrás, para el establecimiento de un Jardín-vivero, de recepción y aclimatación de plantas de ultramar y desde donde se remitirían los pies duplicados al resto de España ${ }^{18}$.

\footnotetext{
"exaltar a Carlos III y a su reinado, y mantener en la sombra la discusión crítica". Y ya puesto, puede consultarse para allende del Pirineo, a L. Roura i Aulinas (1990).

12. F. Guillamas y Galiano (1858), pp. 212-213.

13. P. Barbadillo Delgado (1942), pp. 82-83.

14. A.I. González (1985).

15. Mucho de lo bueno que pueda tener este trabajo se debe a la ayuda inestimable de que he recibido de mi colega y compañero de trabajo Alfonso Alonso, por contra, las deficiencias son sólo mías.

16. A. Lafuente y J.L. Peset (1988), pp. 38-39.

17. Señalemos en provincia de Cádiz el Jardín Botánico-terapéutico de Algeciras sobre el que puede verse "Lista de las semillas que se han remitido desde el Real Jardín para Algeciras sacadas del semillero en 21 de enero de 1785 de plantas oficiales* por el segundo catedrático", Archivo del Jardín Botánico de Madrid (ARJBM), División $l, 4,1,3$. El catálogo consta en realidad de dos listas; la primera de 125 plantas con nombre científico de uso principalmente medicinal, la segunda de plantas usadas en la jardinería de adornos, de la que de 25 de ellas se cita el nombre vulgar dificultando, en consecuencia el conocimiento exacto de la especie. * Oficial: planta usada en las oficinas de farmacia medicinales.

18. Sobre el Jardín Botánico de El Puerto de Santa maría: A.F. García González y V. Rodríguez García (1978) y F.J. Puerto Sarmiento (1988), pp. 198-201.
} 
Hasta ahora, que sepamos, la ubicación del Jardín en Sanlúcar no ha recibido una satisfactoria respuesta. Para Fernando Guillamas el origen del Botánico "tuvo por principio en la casualidad": la remisión a la Sociedad sanluqueña, por parte de Godoy en 1804, de unas semillas de arraigan africano para su aclimatación en Sanlúcar ${ }^{19}$. Pedro Barbadillo está de acuerdo con Guillamas pero hace retroceder la fecha hasta $1802^{20}$; finalmente, para Tomás García ${ }^{21}$, con el que estamos de acuerdo, se trató de una operación de más largo alcance, inserta en la creación de una nueva provincia con capital en Sanlúcar de Barrameda y para cuyo fin, Godoy, fue pródigo en mercedes.

En suma, la clave de la ubicación del Botánico hay que vincularlo a las relaciones personales y predilección por Sanlúcar que mantuvieron dos hombres claves en la política española de finales del siglo XVIII y principios del XIX: Manuel Godoy y Francisco Amorós Ondeano. Godoy, amante primero y esposo después, de la gaditana afincada en Sanlúcar Josefa Tudó y, Amorós, casado con una María Terán, hermana del alma de la Sociedad Económica sanluqueña Francisco Terán ${ }^{22}$.

Pese a todo, de nada hubieran servido las relaciones personales y predilección por Sanlúcar de Godoy y Amorós si al mismo tiempo no hubieran encontrado en la ciudad el valioso entramado humano del que hizo gala la Sociedad Económica sanluqueña ${ }^{23}$.

El punto de partida de esta historia es el nombramiento y aceptación por Manuel Godoy del cargo de regidor perpetuo de la ciudad de Sanlúcar y el título de director y protector Sociedad Económica. Detengámonos en ello.

A finales de noviembre de 1803, Francisco Amorós, llegó a Sanlúcar a tomar posesión de las distinciones en nombre del Príncipe de la Paz. La ciudad se vistió de gala; todos derrocharon generosidad, entusiasmo y se volcaron en hacer de la instancia del comisionado tres días históricos para Sanlúcar: campaña de vacunación contra la viruela, reparto de comida a los presos pobres de la cárcel, reparto

19. F. Guillamas y Galiano (1858), p. 212.

20. P. Barbadillo (1942), p. 83.

21. T. García García (1962).

22. La relevancia de Godoy me liberan de narrar siquiera brevemente la historia del personaje; no así la de Amorós. Nació en Valencia en 1767 y murió en parís en 1848. A los nueve años ingresó como cadete en el ejército. Participó y destacó en el sitio de Oran por cuyos méritos fue ascendido a teniente en 1791 y asimismo en la Guerra contra la Francia revolucionaria. En 1800 ingresó en la Real Secretaría de Estado y Despacho Universal de Guerra como oficial supernumerario donde prestó sus servicios hasta I808; fue nombrado en 1805 miembro de la Junta de Sanidad de Castilla y como militar llegó a alcanzar el grado de Coronel. En el ejército, ejerció de convencido pestalozziano y desde 1790, orientó sus esfuerzos a la labor educativa. Sus esfuerzos en pro de la educación física se vió recompensado por el monarca quién en 1806 le concedió un millón de francos para la instalación del Real Instituto Pestalozziano en donde recibieron educación militares y civiles por el método gimnástico amorosiano. La caída en desgracia de Godoy arrastró a Amorós. A instancias de distintas personalidades cercanas a la Corte se exilió a Francia en 1813.

23. P. Demerson (1976). 
de limosna en el hospital y casa de niños expósitos, suscripción pública para dotar el matrimonio de seis huérfanas apadrinadas por Amorós, donación por Francisco de Paula Rodríguez de 16 aranzadas de pinar destinada para la dote matrimonial de 13 huérfanas, ofrecimiento de Manuel Vázquez de crear una escuela pública de hilado y uso de máquinas, visita a las fábricas y talleres principales de la ciudad, reparto de premios en la enseñanza, siembra de trigo gratuita a los campesinos pobres, corrida de novillos, función de teatro, cantos de arias, dúos y tercetos, iluminación del Jardín, del Consulado, del Ayuntamiento y cena de gala, en la que no estuvo ausente la oratoria, para 240 comensales.

Con todo dos actos sobresalieron por su teatralidad y grandilocuencia: la siembra de pinos en la Algaida y la colocación de la primera piedra en el arrecife de Jerez. El día 28, a las siete de la mañana, las cuadrillas de trabajadores de 22 hacendados con sus capataces al frente y bandera en mano con el nombre de cada uno de sus "amos" y capitaneados por los "amos", los regidores, los jueces consulares, los regidores, el Vicario eclesiástico, el alcalde mayor, varios caballeros y Amorós, se concentraron en la plaza del Cabildo y animados por la música del Regimiento de España se dirigieron al pinar de la Algaida con el propósito de "sembrar un monte que sirviese de recreo, regocijo y provecho a las generaciones futuras”. El ingeniero José Huet marcó el terreno con banderolas en tantas líneas paralelas como cuadrillas concurrían y en menos de tres horas se sembraron 60 aranzadas de piñones. Mientras tanto el Comisionado Amorós escogió un cerro elevado de lugar y sembró, "por su mano", un número de piñones igual al de los años que contaba el Generalísimo y encargó que en lo sucesivo se sembrase uno más cada año en memoria del Príncipe de la Paz. El día terminó en una improvisada comida campestre. Al regreso la comitiva, "al compás de una alegre música", recibió las salvas de tres barcos suecos fondeados en el puerto de Bonanza y a la entrada de la ciudad el regocijo de todo el puehlo. El 29 tocó el turno al arrecife. Preparada la primera piedra de modo que se pudiera colocar en su centro una caja de plomo con monedas y "las noticias políticas y económicas que pueden interesar a las generaciones futuras", bajo la dirección del Vicario, se dispuso para conducirla un carro tirado por seis bueyes ricamente ataviado con collares, guirnaldas, cintas, gallardetes y emblemas que designaban la prosperidad que resultaría de la construcción del camino. Dos niños, vestidos con uniforme de la guardia de honor del Generalísimo, portaban bandejas de plata con algunos de los instrumentos necesarios para la obra. Al llegar la comitiva al Prado de San Sebastián el entusiasmo se apoderó del gentío al punto que se "clamó a una voz que desunciesen los bueyes pues los hombres querían tener la gloria de conducir la primera piedra", se dejó solo una yunta y puesta una maroma todo el pueblo se aprestó a tirar de ella; la mañana terminó con los acostumbrados y "repetidos vivas y aplausos"24.

24. Toda la información de la estancia de Amorós en Sanlúcar procede de "De Ias fiestas rurales y otras 
Finalmente, el día treinta, Junta Extraordinaria de la Sociedad y discurso del comisionado. Amorós se congratula de los éxitos de la Sociedad en el ramo del algodón y llamó a proseguir los esfuerzos en el ramo de la agricultura, con especial atención a las 13.500 aranzadas de marismas incultas; la pesquería y el comercio $^{25}$.

Con fecha de 19 de septiembre de $1804^{26}$ Godoy ofició y remitió a la Sociedad Económica semillas de $A r g a ́ n^{27}$, que este había recibido del cónsul español en Marruecos Antonio González Salmón, para su aclimatación; al mismo tiempo se le hizo saber, que no siendo este el último encargo, la conveniencia de establecer una huerta para la aclimatación de plantas de los "países meridionales" 28 . Poco después la Sociedad recibió la semilla anunciada, acompañada con un barril de su aceite y otras entre las que se encontraba la Lawsonia inermis y Tetraclinis articulata con su correspondiente instrucción sobre sus usos y cultivos ${ }^{29}$. Apenas había pasado un mes cuando los sanluqueños reciben con euforia la Real Orden de 12 de diciembre de 1804 mediante la cual S.M. se había dignado "habilitar este puerto para el comercio extranjero y el de las Américas, erigiendo esta ciudad en capital de provincia dándole por término a Chipiona, Lebrija, Trebujena y Las Cabezas hasta el caño nuevo en la ribera del levante del Guadalquivir y desde allí..."30.

Por Real Orden de 20 de noviembre de 1805 , mientras se ocupaba de los ensayos de las semillas enviadas por Godoy, y a petición de la Sociedad Económica se le concedió la huerta del antiguo convento de los franciscanos para la práctica de

de utilidad pública que se hicieron en S. Lucar a finales del año pasado de $1803^{\prime \prime}, S A A P, \mathrm{n}^{\circ} 422$ y 423 de fechas 31 de enero y 7 de febrero de 1805. Un resumen, en P. Barbadillo Delgado (1942), pp. 836-837. Señalar, finalmente, que existe una contradicción en las fechas de la siembra del pinar de la Algaida; así mientras las noticias del SAAP, nos dice que se realizó el día 29 de noviembre, el propio Amorós $(1804$, p. 37) corrige $y$ da la fecha del 5 de diciembre.

25. F. Amorós (1804), pp. 16-28. Del Discurso de Amorós existe una segunda versión, publicado en Variedades de Ciencias, Literatura y Artes (1804), Vol. II, pp. 205. Si el contenido del artículo es sólo el que resume B. Antón (1865, p. 548), y que lleva por título "Discurso leído por D. ..., en la Sociedad Económica de Sanlúcar de Barrameda el 30 de noviembre de 1803, sobre el modo de convertir en navazos las arenas voladoras", se trata tan sólo de la reproducción de la nota 12 (sobre los navazos), del Discurso publicado en Cádiz en 1804.

26. F. Guillamas y Galiano (1858, p. 212) fecha este oficio en 16 de diciembre de 1804 . Evidentemente se equivoca Guillamas dado que el José $\mathrm{M}^{a}$ Romero (Discurso pronunciado en la Sociedad Sanluqueña en enero de 1807, AJBM, División I, 22, 7, 4) lo fecha en 19 de noviembre de 1804.

27. Arbol africano de cuya semilla se "extraía mucho, y muy buen aceite". Cf. J. M $M^{a}$ Romero (Discurso pronunciado en la Sociedad Sanluqueña en enero de 1807). Al hilo del envío de esta planta cabe señalar el interés despertado en el Gobiemo por eI viejo continente africano: envio de plantas, al Jardín por los cónsules de Marruecos, Trípoli y el Cairo y, desde luego, las andanzas del botánico y aventurero Domingo Badía. Véase: M. Godoy (1965), vol. II, pp. 28-37; J. Mercader Riba (1965) y F. de las Barras de Aragón (1911).

28. J.M Romero, Discurso pronunciado en la Sociedad Sanluqueña en enero de 1807, AJBM, División $1,22,7,4$.

29. Ibid.

30. L. Mananteau et alii (1991), vol. II, p. 56. 
los ensayos. El terreno resultó demasiado inclinado por lo que, finalmente, se instaló en el de las monjas de Regina Caeli, ampliado con 18 aranzadas del baldío de el Palmar de San Sebastián de propiedad municipal ${ }^{31}$. Por fin por Real Orden de 3 de mayo de 1805 se dio luz verde al Botánico Sanluqueño ${ }^{32}$ que fue acompañada por otra de 18 de diciembre mediante la que se ordenó el establecimiento de veinticuatro Jardines botánicos en diferentes sitios de la península ${ }^{33}$.

La puesta en marcha del Botánico sanluqueño tropezó con el siempre espinoso problema de la financiación del que ya nos ocupamos.

\section{FINANCIACIÓN Y ORGANIZACIÓN DEL JARDÍN: LA LARGA MANO DE GODOY}

El problema más grave que tuvo que resolver el Botánico fue, como de costumbre, el de la financiación, en la que intervino directamente Godoy ante el Rey para allanar el camino. El Rey ante la petición de la Sociedad de Sanlúcar, accedió a conceder el producto del arbitrio sobre las semillas extranjeras introducidas por los puertos del Reino de Sevilla, "siempre que no se ofrezcan graves reparos por la hacienda" 34 . Pasada la Real Orden al Ministerio de Hacienda este puso cinco reparos que resumimos a continuación:

1. Que si el Jardín es muy a propósito para la aclimatación de plantas y semillas, lo mismo pensarán desde las provincias de Sevilla y Cádiz y juzgarán más útil tenerlo en sus respectivas capitales y con el mismo arbitrio.

2. Que siendo evidente que en Sevilla faltan "granos para el consumo" y no pudiéndose esta surtir con los granos "nacionales aún en años de buena cosecha", el arbitrio se sobrecarga sobre un producto de primera necesidad.

3. Que el arbitrario propuesto entra en contradicción con la misma política Real, que tiene a bién suspender todo tipo de impuesto sobre la introducción de granos extranjeros cuando lo considera absolutamente necesario para disminuir el "hambre y la calamidad".

4. Que el dinero que se estima necesario para el mantenimiento del Jardín, 60.000 reales, es desproporcionado en relación a Io que rinden por el arbi-

31. J.M." Romero, Discurso pronunciado en la Sociedad Sanluqueña en enero de 1807, AJBM, División 1, 22, 7, 4 y también F. Guillamas y Gaiano (1858), p. 83.

32. De esta Real Orden nos enteramos por la carta que el primer director Botánico, Francisco Terán, dirigio con fecha 22 de julio de 1805 al Príncipe de la Paz. Esta carta, al igual que todas las que citemos a continuación, se encuentra en el Archivo Municipal de Sanlúcar de Barrameda (AMSB) y fueron donadas, no ha mucho, por un vecino de Puerto Real.

33. J.M ${ }^{a}$ Romero, Discurso pronunciado en la Sociedad Sanluqueña en enero de 1807, AJBM, División $I, 2,7,4$.

34. AMSB, Carta de Franciseo Terán al Príncipe de la Paz fechada en Sanlúcar el 22 de agosto de 1805. 
trario reclamado las aduanas del Reino de Sevilla: 346.711 reales en 1803 y 916.385 en 1804.

5. Que considera de utilidad un jardín para plantas, pero inútil, si se destina a la aclimatación de animales exóticos, sobre todo, cuando España, tiene otros "connaturaliados ya con nuestro clima y pastos que nos envidian los extranjeros, y cuyo aumento y mejora será mucho más interesante" 35 .

El monarca, tras oír las alegaciones de hacienda, por Real Orden de 18 de mayo de 1806, anuló la concesión del arbitrio ${ }^{36}$.

La Sociedad Económica elevó nueva instancia al Rey el 22 de julio de 1806, argumentando a favor del arbitrio; el mismo Godoy intervino en el asunto como prueba la carta que este dirigió al director del Botánico Francisco Terán:

"Enterado de la carta de V.S. de 22 del pasado y de la representación que había hecho por encargo y a nombre de la Sociedad, con el fin de probar que no podía elegirse otro arbitrio mejor para sostener el establecimiento del Jardín experimental de aclimatación, que el impuesto sobre las semillas extranjeras, y opinando yo en este particular desde el principio del mismo modo que V.S., apoye sus sólidas reflexiones y exactos principios, e hice ver al Rey por la vía de Estado quan conducente era señalar el arbitrio propuesto para la dotación de ese Jardín. Persuadido el Real ánimo de S.M. por las nuevas consideraciones que se le hicieron presentes se ha conformado en un todo con mi dictamen, y ha mandado lo conveniente para que se lleve a efecto..." $"$.

Hacienda, no tuvo más remedio que conformarse al parecer de "Señor Generalísimo" y ordenó los siguientes adeudos sobre los granos y semillas introducidos por los puertos del Reino de Sevilla: treinta y cuatro maravedíes por cada arroba de frijoles, habichuelas, judías y arbejones; doce por cada arroba de habas y maíz; diecisiete por cada arroba de arroz y el mismo adeudo por cada fanega de trigo o cebada y, finalmente, cincuenta y uno por cada quintal de harina de trino ${ }^{38}$.

Paralelamente, Amorós, se dedicaba a preparar la apertura solemne del Botánico. A instancia suya, la Sociedad sanluqueña acordó: 1) Construir una urna sencilla de plata en donde se depositarían las reales ordenes y el lema: Triunfo de la agricultura de España en el establecimiento de un jardín botánico experimental, y de aclimatación en Sanlúcar concedido por el Rey en 20 de noviembre de 1805 a

35. Las alegaciones de Hacienda pueden verse en el AMSB junto a los papeles que venimos citando.

36. AMSB, Carta de Francisco Terán al Príncipe de la Paz fechada en Sanlúcar el 22 de agosto de 1806.

37. AMSB, Carta del Príncipe de la Paz fechada en Madrid el 15 de agosto de 1806.

38. AMSB, Carta al Señor subdelegado de Rentas de Sanlúcar de Barrameda, fechada en San Ildefonso el 21 de agosto de 1806. 
influxos del Excmo. Sr. Príncipe de la Paz; 2) Dotar todos los años el matrimonio de un labrador honrado con cien ducados debiendo ser el padrino el capataz de labor de campo más anciano del pueblo a quién se le dará una onza de oro para que obsequie a los novios en nombre del Generalísimo; 3) Junta anual solemne en donde se hará resumen de las actividades del Botánico y 4) Solicitar a S.M. el nombre de Jardín de la Paz para el botánico sanluqueño lo que efectivamente fue concedido por Real Orden de 11 de abril de $1806^{39}$.

Salvado el obstáculo de la financiación, la dirección del Jardín correspondió a una comisión compuesta por Francisco Terán, Juan Antonio Martínez y Francisco de Paula Rodríguez y para el diseño del Botánico se comisionó a Esteban Botelou ${ }^{40}$.

En agosto de 1806 fue dotado de personal: jardinero mayor, Ramón López, que fue sustituido de forma inmediata por Esteban Delgado y como profesor de agricultura, Don Mariano Lagasca ${ }^{41}$. Por no haber admitido Lagasca la plaza, la comisión, propuso a Donato García ${ }^{42}$ que tampoco pudo hacerse cargo de la Cátedra por estar nombrado para el Jardín de Tenerife; finalmente se encargó de la misma Don Simón de Roxas Clemente ${ }^{43}$.

El terreno lo dividió Botelou en ocho partes, según nos informa J.Ma Rome$\mathrm{ro}^{44}$.

En la primera, una pequeña escuela de botánica suficiente a enseñar la agricultura práctica; en la segunda, el cultivo de cereales y ensayos y experimentos para su mejora y propagación de las especies y variedades más útiles; en la tercera, plantas dirigidas a la formación de prados artificiales -tanto en secano como en regadío- y que sirvan como abono en verde o alimentación del ganado; en la cuarta, plantío de las variedades de vides conocidas y ensayos de las más productivas y apropiadas para la elaboración de vinos; en la quinta, las plantas que tengan relación con las artes y oficios y aquellas otras no comunes que tengan relación con

39. J.M $\mathrm{M}^{3}$ Romero, Discurso pronunciado en la Sociedad Sanluqueña en enero de 1807, AJBM, División $I, 22,7,4$.

40. Ibid.

41. ARJBM, División. I: 57, 4, 16; 57, 6, 7 y 22, 6, 16, "1806, Carta de F. Terán a M. Lagasca en la que le comunica la propuesta de nombramiento como profesor del Jardín de Canarias"; "1806-1808, Borrador de una carta de $\mathrm{M}$. Lagasca en la que expone algunas observaciones en contra de su nombramiento para enseñar en el nuevo Jardín de Sanlúcar de Barrameda" y "1806, Borrador del oficio de M. Lagasca a P. Cevallos sobre el nombramiento y los fondos para el Jardín de Sanlúcar de Barrameda".

42. ARJBM, División I, 22, 6, 19, “I806, Real Orden a F.A. Zea que le comunica el nombramiento de D. García como profesor de agricultura y botánica en el Jardín de aclimatación de Sanlúcar de Barrameda".

43. Ibid. y F. Guillamas y Galiano (1858), p. 213 y AMSB, Carta del Príncipe de la Paz a Pedro Cevallos, fechada en Madrid el 15 de agosto de 1806. En esta misma carta nos enteramos que la sustitución del jardinero mayor Ramón López se debió a no ser este del agrado de Godoy: acababa de salir de la cárcel por "sospecha de infidelidad que ha dado en la sustracción de algunas plantas". Se equivoca A.I. González (1985), p. 31) cuando sostiene que la sustitución del jardinero fue debida a una "indisposición" Je Ramón López.

44. J.M Romero, Discurso pronunciado en la Sociedad Sanluqueña en enero de 1807, AJBM, División I. $22,7,4$. 
la medicina; en la sexta, los plantíos de árboles y arbustos de frutas más preciosos que se conozcan y ensayos de los métodos más sencillos para su propagación mediante injertos; en el séptima, los árboles de maderas más propios para la construcción de bajeles, artes y demás usos y, en la octava, la más abrigada del Jardín, los invernaderos para la aclimatación de los vegetales exóticos de conocida utilidad. Finalmente y en estrecha relación con todas las actividades señaladas más arriba, mejoras y propagación del ganado caballar y lanar indígena y experimentos y ensayos dirigidos al cruce de razas y castas.

\section{LA BOTÁNICA AL SERVICIO DE LA PRODUCCIÓN AGRARIA, GANADERA Y FORESTAL}

A juzgar por la organización del Botánico sanluqueño, este está muy alejado de la botánica considerada como simple "lista metódica" de los caracteres de las plantas, con indicación de los lugares donde se encuentra y del tiempo en que florecen fructifican y de la que tan certeramente se quejaba los Simón de Roxas Clemente $^{45}$. Para Roxas existen botánicos "vulgares" y botánicos de "provecho"; los primeros dedicados al estudio de las plantas mas "útiles" a la agricultura y, los segundos, huyen de los "campos cultivados" y si alguna vez entran en ellos es para "buscar las plantas silvestres que el labrador detesta" y solo con el ánimo de "clasificarla y averigurar el nombre científico".

Como ha señalado F.J. Puerto Sarmiento ${ }^{46}$, la botánica española del siglo XVIII prefirió involucrarse en el ámbito sanitario y en el puramente científico, a la par que desdeñó la agronomía y la enseñanza de la agricultura. Hubo que esperar a la sustitución de Gómez Ortega por Cavanilles al frente del Botánico Madrileño, para que una nueva generación de botánicos (Roxas Clemente, Esteban y Claudio Botelou, Lagasca, etc.) pusieran sus conocimientos científícos al servicio de la mejora agrícola del País.

Desde este punto de vista, no hay mas que concluir que el Botánico sanluqueño, fue un botánico de segunda generación; un botánico de "provecho" y por fín volcado, a la mejora de la producción agraria y forestal ${ }^{47}$.

En la Junta general de la Sociedad Económica sanluqueña celebrada solemnemente a primero de enero de 1807, el discurso inaugural corrió a cargo de Henrique Galafate que glosó los objetivos del Botánico:

45. S. de Roxas Clemente (1807), pp. 1-2.

46. F.J. Puerto Sarmiento (1988), pp. 9-28.

47. Los comentarios de Clemente en "Sobre el centeno que se cultiva en Tahal y puede interesar a la agricultura: con algunas reflexiones acerca de las variedades vegetales y la necesidad de estudiarlas", en SAAP, $n^{\circ} 485,17$ de abril de 1806. 
"¿Y que hombre sensato no deberá prometerse tan ventajosos resultados de la erección del «Jardín de la Paz»? ¿De un Jardín que seguirá una correspondencia importante con el de la Metrópoli, con el de chile, Santa Fe y con el de Tenerife, puntos principales en que nuestro sabio Gobierno se propone restaurar la ciencia más útil a la Monarquía? ¿De un Jardín en que se enseñará prácticamente la agricultura por principios ilustrados, y que nos hagan abandonar mil erradas prácticas, que por una rutina hemos conservado por mucho tiempo en detrimento de nuestro intereses? ¿De un Jardín que nos ofrecerá millares de semillas y plantas exóticas con las cuales minoraremos nuestras necesidades, aumentaremos los frutos de consumo y alimenticios, y nos proporcionaremos la riqueza y la abundancia?"48.

Y Francisco Romero, al que correspondió historiar los orígenes del Botánico y la organización de mismo:

"Debiendo el referido establecimiento ser un semillero, o llamándolo mejor, un almacén general, que pueda proporcionar a los pueblos del Reino, y a los particulares las producciones más preciosas, y menos comunes, tendrá siempre abundante provisión de semillas, estacas, y aún plantas vivas para satisfacer los deseos de los que quieran enriquecer su país con estos hermosos dones de la naturaleza, aunque con aquellas restricciones, que las circunstancias exijan. Siendo uno de los fines del Jardín el plantío de árboles útiles procuraran los comisionados en la dirección poblar los inmensos terrenos, que se hallan desperdiciados en esta nueva Provincia, y que son tan propios a la vegetación de alguno de aquellos, teniendo cuidado de acomodar la especie a su terreno, y clima adecuado"49.

Romero volvió a insistir que el "principal objeto" del jardín era el "adelanto de la agricultura" y señaló la importancia que en ello había de tener las mejoras en la "construcción y manejo" de nuevos instrumentos y aperos agrícolas. En modo alguno se trató de un discurso retórico dedicado a la galería. En efecto, Francisco Terán entró en contacto con Jacobo Gordon que acababa de importar de Inglaterra "varios arados y otras máquinas" y acompañado de Esteban Botelou, Juan Antonio Martínez y José Huet pasaron a Jerez y lograron que Gordon se comprometiera a ensayar los arados en Sanlúcar con motivo de la inauguración del Jardín ${ }^{50}$.

48. Este discurso lo publicó el Correo de Xerez, el 28 y 31 de diciembre de 1807 y puede leerse en el tomo de Varios, $\mathrm{n}^{2} 60$ de la Biblioteca Colombina. Véase: T. García García (1962), p. 4.

49. J.Ma Romero, Discurso pronunciado en la Sociedad Sanluqueña en enero de 1807, AJBM, División $1,22,7,4$.

50. ARJBM, División 1, 22, 7, 4. 
Una vez mas, el entusiasmo fue paralelo a la generosidad. Los jefes y oficiales del Regimiento de Dragones de Lusitania entregaron a la dirección del Jardín la suma de diez mil reales para la compra y propagación de los nuevos arados y Don Jacobo Gordon, "deseoso" de contribuir la festividad consagrada a la "restauración de la agricultura", donó un ejemplar de los distintos arados e instrumentos ${ }^{51}$.

Pero quizás nadie mejor que el propio artífice del Botánico, Godoy, para que nos informe del nuevo rumbo de la botánica española. Un Real Decreto se ordenó creación en todas las provincias de Institutos Normales de agricultura práctica dotados cada uno con un campo y un jardín botánico donde se practicase la enseñanza, se ensayasen los descubrimiento, método, utensilios e instrumentos nuevos que nos llegasen de otras partes, se reuniesen todas las producciones conocidas del País, se educasen las silvestre y se explorase su importancia, se aclimatase las exóticas, se instruyesen a los alumnos en la fisiología vegetal, en el discernimiento de terrenos, en los medios de fecundarlos según sus calidades y mejorar sus producciones y en todo lo demás que condujese a propagar entre los pueblos los conocimientos físicos, industriales y económicos ${ }^{52}$. Mientras se hallaban los medios no gravosos de realizar la nueva empresa, el jardín Príncipe de la Paz vino a ser la avanzadilla de la política del Gobierno:

"Daba ya gran estímulo a esta obra el suceso prodigioso del Jardín de Sanlúcar, primer ensayo que yo hice de esta suerte de establecimiento, tan necesarios y tan útiles en medio de un país como España, donde la grande vocación del pueblo y el fundamento principal de la riqueza es el cultivo de la tierra" ${ }^{153}$.

En el corto espacio de unos años la labor desarrollada por el Botánico fue inmensa. En febrero de 1806 se verificaron las siembras semillas y plantíos de estacas y plantas vivas remitidas por el Real Jardín por orden del Príncipe de la Paz. Pronto formaron un gran depósito de semillas: Botelou, llevó desde Madrid especies; unas las habían sido remitidas anteriormente desde el interior de Africa el cónsul español en Trípoli y, otras muchas de los Jardines de Aranjuez. El director y Subinspector del Real Cuerpo de ingenieros aportó algunas semillas americanas; Bernabé Portillo, dos paquetes de semillas de la Hierba Guinea; Antonio González Salmón, cónsul de S.M. en Marruecos dos cajones, el uno con las Piñas de Lheriz y de Cedro, y, el otro, con la simientes del árbol que produce la Goma Anther $a^{54}$.

51. Ibid. y M. Godoy (1965), vol. II, pp. 143.

52. M. Godoy (1965), vol. II, pp. 143-144.

53. Ibid., p. 144.

54. J.M ${ }^{a}$ Romero, Discurso pronunciado en la Sociedad Sanluqueña en enero de I807, AJBM, División $I, 22,7,4$. 
En los dos años siguientes continuaron las siembras a un ritmo de modo que, hacia finales de 1808 en número de árboles plantados podían acercarse a los 25.000 ejemplares y decenas de especies:

CUADRO I

INVENTARIO DE ARBOLES DEL BOTÁNICO SANLUQUEÑO $1809^{55}$

\begin{tabular}{|c|c|c|c|}
\hline Especies & $\mathrm{N}^{\circ}$ & Especies & $\mathrm{N}^{\mathrm{c}}$ \\
\hline Algarrobo de comer ...... & 4.000 & Bignonias Catalpas .... & 123 \\
\hline 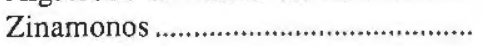 & 3.682 & 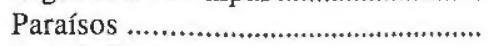 & 120 \\
\hline Alamos negros & 2.779 & Membrillos ..................... & 100 \\
\hline Acacias de 3 puntas .......................... & 2.340 & Mimbreras ................... & \\
\hline Chopos de Lombardía .......................... & 2.173 & Chopos del País ............... & 7 \\
\hline Algarrobo de Chile & 1.670 & Guayacanas ............. & 6 \\
\hline Fresnos todas espec. & 1.274 & 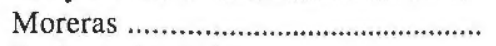 & 60 \\
\hline 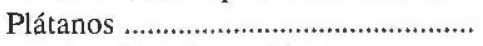 & 823 & 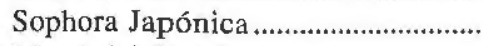 & 48 \\
\hline Perales, Ciruelos y Nisperos ............ & 684 & 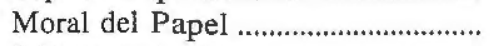 & 42 \\
\hline Nogales comunes y Americ. .............. & 621 & Bálsamos del Perú .... & 42 \\
\hline 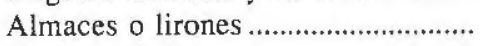 & 530 & 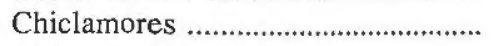 & \\
\hline dulces & 439 & 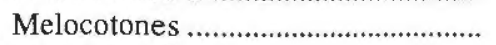 & \\
\hline 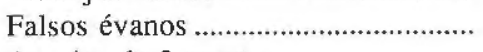 & 423 & 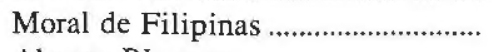 & \\
\hline Acacias de 2 puntas & 413 & Alamos Blancos...... & \\
\hline Mangles de Lusiana ……........................ & 250 & Robles & 3 \\
\hline Chopos de Carolina & 202 & 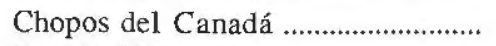 & 26 \\
\hline 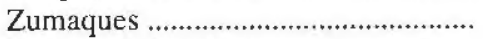 & 176 & 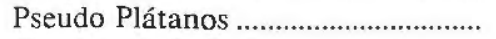 & 18 \\
\hline Sauces de Babilonia .............................. & 170 & 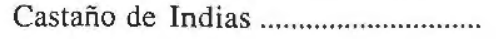 & 13 \\
\hline 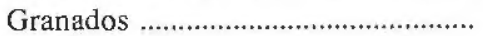 & 139 & & \\
\hline
\end{tabular}

En el inventario no fueron incluidos 1.168 árboles plantados en las calles del Jardín, tampoco centenares de mimosas, arbustos, y "plantas oficinales, tan últiles a la humanidad" 56 .

La familia de las plantas dominantes en el inventario son las leguminosas (25\% del total de especies), seguida de las Salicáceas $(17,5 \%)$ y las rosáseas (15\%). Como sabemos las leguminosas y las rosáceas son familias de plantas con gran número de especies de interés agrícola. Todas las rosáseas del inventario son árboles frutales (manzano, perales, nísperos, melocotones, etc.). De entre las leguminosas,

55. Estevan Delgado, Relación de los árboles existentes de varias clase, en el Real Jardín de Aclimatación de Sanlúcar de Barrameda, en el año de 1809, dada por el jardinero mayor de dicho, Don Estevan Delgado, en 16 de agosto del año ya citado. Puede verse fuera de catalogación en el AMSB.

56. Estevan Delgado, Relación de los árboles existentes de varias clase, en el Real Jardín de Aclimatación... 
algunas, producen hojas con propiedades forrajeras (Acacias de dos puntas, algarrobo de Chile) y, de otras, se obtienen legumbres y semillas como alimento para el ganado (algarrobo, acacias de tres puntas, algarrobo de chile). Frutas para el consumo humano son el nogal, el naranjo dulce o el almez (Celtis australis). Abundan, asimismo las plantas de interés industrial y muchas de ellas con propiedades tintóreas: nogal, sofora japónica, morera, castaño de indias, Eleagnus angustifolia; curtientes: algarrobo, álamo blanco, zumaque y otros usos, como por ejemplo, la hoja de la morera para alimentar a los gusanos de seda, la morera del papel (Broussenetia papyrifera) o las mimbreras para la obtención del mimbre.

Lugar destacado lo ocupa también en el inventario los árboles con estricta vocación forestal de utilidad en la ebanistería, carretería o construcción: Chopos, álamos, fresnos, almeces, robles y, que evidentemente, conectan con el retroceso de la masa arbórea durante toda la edad moderna y una de las inquietudes de la ilustración española como pone de manifiesto la traducción temprana de la obra de Duhamel de Monceau Tratado del cuidado y aprovechamiento de los montes y bosques, corta, poda, beneficio y uso de sus maderas y leñas... y Compendio del tratado sobre siembras y plantios de árboles y su cultivo o medios de multiplicar y criar árboles; de plantarlos en espesillos y alamedas; de formar montes y bosques y su cultivo o medios de multiplicar y criar árboles; de plantarlos en espesillos y alamedas; de formar montes y bosques y restable los deterioros... ${ }^{57}$, o la misma actividad de la Sociedad Económica sanluqueña plantando miles de pinos en la Algaida o la insistencia de Francisco Terán en dotar al Jardín de "semillas de árboles y plantas útiles", como los pinos de Cuenca, Suecia y otros países, apropiados para la "construcción" de "bajeles", "edificios", "arboladuras de navíos y toda clase de tablazón" 58 . Finalmente, no cabe olvidar, en relación con la visión estética que de la naturaleza tenían los ilustrados ${ }^{59}$, las numerosas especies y ejemplares de carácter ornamental para paseos urbanos, jardines públicos y caminos: chopos de lombardía (2.173), álamos negros (2.779), sauce de babilonia (170), castaño de indias (13), sóphora japónica (48), etc.

Importa subrayar, en contraposición a la preocupación botánica-farmacéutica de los anteriores Jardines, el hecho de que el inventario sólo contenga una sola especie cuya propiedad fundamental sea la curativa: el bálsamo del Perú con cuarenta y dos 42 ejemplares o, lo que es lo mismo, el 0,17 por ciento sobre el total de inventario. Es asimismo interesante señalar, en contraposición al empeño anterior por la flora de América del sur, la inclusión de la flora Norteamericana (el chopo de Carolina, el mangle de Luisina y las acacias de dos y tres puntas del Canadá),

57. Duhamel de Monceau (1773-1774) y (1805).

58. AMSB, Carta de Francisco Terán al Príncipe de la Paz, fechada en Sanlúcar el 22 de agosto de 1806.

59. Véase por ejemplo el prólogo de C. Ortega (pp. I-XII) a la obra de Duhamel de Monceau (1805) y una introducción acerca de "La imagen de la naturaleza a fines del siglo XVIII" en L. Urteaga (1987), pp. 174-192. 
Centroaméricana (el guyacán) y de la Europa oriental, próximo y lejano oriente: falso ébanos, Castaño de indias, granados, membrillo, Melia azederach, Sóphora japónica, Moral del papel, Moral de filipinas, Naranjo dulce y el Seudo plátano.

Junto al inventario comentado, como anunciábamos más arriba, en los Archivos del Real Jardín Botánico de Madrid existen varias listas de plantas que, sumadas todas, debieron de ser el completo inventario del Jardín sanluqueño.

La primera de las listas incluye, en un folio manuscrito, atribuible al a Simón de Roxas Clemente, las "Semillas recogidas de las plantas que hoy existen en el Jardín" ${ }^{60}$ que suman 61 especies. En la lista abundan (41\%) las labiadas, leguminosas y gramíneas; en su mayoría herbáceas y sólo algunas arbustivas. Por su origen, la mayor parte de las especies son europeas y otras muchas americanas. Respecto a la utilidad, hay plantas medicinales (Leonurus cardiaca, Phytolocca decandra, Hyssopus officinalis, etc.), algunas ornamentales (Dahlia coccinea, Tradescantia electa, etc.), comestibles (Dahlia rosea, Physalis pubescens, Sinapis alba, etc.) industrial (Lygeum espartum, Isatis tinctoria, Genista tinctoria, Indigofera tinctoria, Ligustrum vulgare, etc.) y gran número de forrajeras (Melitotus indicus, Medicago lupulina, Holcus mollis, Phalaris arundinacea, Anthoxantum odoratum, Agrostis miliacea, Elymus arenarius, etc.).

Una segunda lista, atribuible también a Roxas, recoge 92 especies acompañada de indicación sobre el período y volumen de siembra y que en nada cambian lo que hasta aquí hemos afirmado respecto a la orientación del botánico sanluqueño: leguminosas y gramíneas de interés forrajero, árboles de vocación forestal y otras plantas de interés medicinal y ornamental ${ }^{61}$.

La tercera lista es de mucha mayor importancia dado que incluye 223 especies que, según acompaña la nota, fueron "remitidas desde Madrid; y conducidas por Don Esteban Botelou". Más del 50 por ciento de las especies son Europeas y casi en su totalidad herbáceas, muchas arbustivas y pocas arbóreas. Respecto a su utilidad: forrajera, comestible por su tallo, raíces o fruto; industrial, medicinal y ornamental ${ }^{62}$.

Finalmente, sabemos por Simón de Rojas Clemente que el Jardín llegó a contar con una colección completa de todas las vides de Andalucía, la Mancha y Rioja y una pequeña colección de 10 variedades de trigos españoles ${ }^{63}$.

Con ser ya ingentes las tareas y proyectos del Jardín respecto a la aclimatación y cultivos de plantas indígenas y exótica, el proyecto inicial del Jardín incluyó entre sus objetivos, pese a los reparos del Ministerio de Hacienda ${ }^{6+4}$, la aclimatación de

60. ARJBM, División 1, 22, 7, 1, "Semillas recogidas de las plantas que hay existente en el Jardín". 61. A.I. González (1985), p. 33.

62. ARJBM, División I, 22, 7, 1 "Lista de semillas remitidas de Madrid (por el Real Jardín Botánico); y conducidas por Estevan Botelou en el año de 1806".

63. Simón de Roxas Clemente, Producciones vegetales de Sanlúcar de Barrameda (manuscrito), en ARJBM, División I, 15, 2, 4. 
animales exóticos. En las fiestas celebradas por la Sociedad a primero de enero de 1807, F. Romero, tras señalar el cultivo de las plantas y árboles evocó:

"Esto que se dice de los vegetales podrá extenderse también a los animales, quando cuente entre ése riquezas las cabras de Angora, ya aclimatadas cerca de Madrid, las vicuñas, alpacas, huanacos y llamas que proveyéndolos de lanas y pelos aumenten su comercio e industria y cuya aclimatación se ha intentando en otras ocasiones; los cíbolos y bisontes animales superiores al buey en el servicio, y utilidades. Este animal colosal sería un tesoro para la agricultura... serán utilísimos los camellos, los gusanos de seda de Cochinchina, que no exigen cuidado alguno; la cochinilla o grana, que con tanta facilidad, y propagarse aquí, resecto lo bien que se dan los Nopales, o tunas y lo mismo de muchos otros".

No llegaron a tanto. A iniciativa de la Junta Rectora del Jardín se embarcaron desde el Perú 8 vicuñas, 8 llamas y 8 alpacas machos y hembras; el buque que las conducía fue apresado por los "ingleses y llevado a unas islas donde permaneció por mucho tiempo hasta la paz con Inglaterra; que en tanta y tan larga navegación y demora murieron 5 vicuñas, 5 llamas y 6 alpacas, principalmente en la estación en que estuvieron prisioneros". A Sanlúcar sólo llegaron a desembarcar, 3 vicuñas machos y hembras, 3 llamas de ambos sexos y 2 alpacas machos. Para el sanluqueño Colon, del que proceden estos datos, los animales llegaron a Sanlúcar después de la representación Sanluqueña del Motín de Aranjuez y fueron colocados en los restos del Jardín tan pobres en pastos que fue necesario sacarlos a "pacer las yerbas de los baldíos en los alrededores de la población" y al poco tiempo parieron las vicuñas y las llamadas y al cabo de tres años todos los animales murieron ${ }^{65}$. Sin embargo por notas sueltas de Terán escritas en 1820, este afirma, dirigiéndose a Roxas Clemente: "Usted vio que en el estado de domesticidad, se cruzan todas estas castas, resultando un nuevo género de lana superior al de la vicuñas de los hijos de ella y de alpaco, que llegaron a Sanlúcar en $n^{0}$ de tres a la que dimos el nombre de Alpaca-Vicuñas. También vimos una llama preñada de un Alpaco"66; de manera que, o se trata de dos remesas de animales o desde luego está equivocado Colón cuando afirma que estos llegaron después del Montín de Aranjuez.

64. Las alegaciones de Hacienda pueden verse en el ASMB junto a los papeles que hemos venido citando más arriba.

65. La información sobre estos animales en, Archivo Municipal de Cádiz (AMC), Sociedad Ecómica Gaditana (SEGAP), Leg. 3.420, "Carta de Juan Colón a la SEGAP, fechada en Sanlúcar el 4 de diciembre de 1843". La idea de aclimatar alpacas y vicuñas no era desde luego nueva. En un artículo del SAAP de fecha de 22 de diciembre de 1801, tras anumerarse las utilidades de las "llamas de vicuñas" propuso el autor convertirlas en materia de comercios, como asimismo, conservar y multiplicar la especie trayendo a Europa "algunas manadas". Véase: F. Zea, "De las vicuñas", SAAP, 22 de octubre de 1801.

66. AJBM, División I, 58, 3, 9. 
De todas formas interesa subrayar mas el hecho de las cruzas con éxito y su aclimatación en la que desde luego está de acuerdo Colón cuando en carta remitida a la sociedad económica de Cádiz ofreció las siguientes consideraciones: Si los animales, resistieron el "Vigor de las estaciones en su varia y larga travesía" y si estos hubiesen encontrado el "cuidado, esmero y tino, que de suyo exige tan importante aclimatación, acaso se habrían obtenido los ventajosos resultados que se propusieron en este ensayo". Colón aprovechó la ocasión para manifestar su opinión acerca de las posibilidades de aclimatación de las vicuñas, llamas y alpacas en la que en aquellos momentos se interesaba la Sociedad Económica gaditana y sugirió que por tratarse de animales propio de las regiones elevadas y frías de la cordillera de los Andes sería necesario para intentar su aclimatación se "pongan en circunstancias, sino semejantes, por lo menos análogas a su clima nativo, y que sólo los hijos que nazcan en este país, sean los que poco a poco se vayan naturalizándose al temperamento de las tierras bajas, pero siempre en terrenos que ofrezcan situaciones sombrías, de que gustan naturalizándose al temperamento de las tierras bajas, pero siempre en terrenos que ofrezcan situaciones sombrías, de que gustan naturalmente para huir del ardor del sol, como se observó en los que estubieron en el Jardín" de Sanlúcar y esto mismo confirmó el ensayo que se hizo en la Casa de Campo. Termina Colón su carta su carta sugiriendo como el lugar más a propósito para el intento de aclimatación la Serranía de Ronda ${ }^{67}$.

Finalmente, en el Botánico sanluqueño también tuvo cabida otras ciencias útiles: en 1807, por orden real fueron remitidas al Jardín "una colección de minerales" que el propio Simón de Rojas Clemente se encargó de seleccionar ${ }^{68}$.

\section{LA MUERTE DEL BOTÁNICO: LA VERSIÓN SANLUQUEÑA DEL MOTÍN DE ARANJUEZ Y LOS TÍMIDOS INTENTOS LIBERALES}

Pocas oportunidades tuvo el Botánico sanluqueño. El Motín de Aranjuez y la caída de Godoy eu 1808, tuvo su propia representación en Sanlúcar. Un contemporáneo nos resume los acontecimientos:

“...los sucesos políticos del año 1808, que derribaron al Príncipe de la Paz, protector de todas las mejoras intentada en este suelo, y que dieron motivo a que todo lo que llevaba su nombre, o lo que había tratado de fomentar, se destruyese y aniquilase, llegando este encono hasta perseguir a los hombres celosos e ilustrados que estaban al frente de todas estas empresas “699.

67. Ibíd.

68. A.J. Barreiro (1992), p. 127.

69. AMC, SEGAP, Legajo 3.420, "Carta de Juan Colón a la SEGAP y fechada en Sanlúcar el 4 de diciembre de I843". 
Pero sigamos los sucesos más de cerca. El domingo 27 de mayo "el populacho bárbaro... en odio al favorito y a todo lo que el había fundado fuese bueno o malo"70 comenzó a recorrer las calles sanluqueñas; se dirigieron al Consulado en demanda del retrato de Godoy que fue destrozado y quemado; posteriormente, un gran gentío, visitó la casa del Francisco Terán en busca del busto del "generalísimo" destinado al Jardín, el busto lo amarraron a un mulo, lo pasearon por toda la ciudad y lo destrozaron a palos; igual suerte corrieron los retratos de la casa del maestro de dibujo Juan José Beécquer y lo mismo hicieron con un bote salvavidas, donado por Godoy, de los prácticos de la barra del río ${ }^{71}$. A las tres de la tarde, la muchedumbre se dirigió al Botánico y "fue robado y quemado, por titularse Jardín de la Paz"72; el día terminó con la destrucción del obelisco, levantado años atrás para conmemorar la toma de posesión de Godoy como regidor perpetuo de la ciudad. El lunes 28 continuó la fiesta: un pelele que representaba a Francisco Terán recorría las calles para ser quemado a toque de campanas y con contento con ello se disponían a visitarlo con intenciones nada pacíficas; la intervención del vicario Rafael Colón, Francisco de Paula Rodríguez, Francisco de Paula Colón, Marqués de Casa-Arizón y otros, probablemente evitó desgracias personales. Las autoridades, finalmente, encauzaron las iras hacia lo festivo: corrieron los toros y el vino $y$, a fin de evitar posteriores desmanes, el ayuntamiento mando colocar nuevos rótulos en el arrecibe y en el Jardín de Aclimatación: "Pertenece(n) al Rey"73. Los desmanes en el jardín no llegarían a tanto como prueba el inventario de $1809^{74}$.

El Gobiemo de Fernando VII no quiso saber nada del Botánico y hay que esperar al Trienio para que volvamos a tener noticia del Jardín. A finales de 1820 se reinstala la Sociedad Económica sanluqueña regida por los mismos estatutos de su anterior época. Fue su primer presidente José Huet y Manuel Salazar su secreta-

70. F. Guillamas y Galiano (1858), p. 213.

71. P. Barbadillo (1942), p. 769.

72. AMC, SEGAP, leg. 3.420, "Carta de Juan Colón a la SEGAP y fechada en Sanlúcar el 4 de diciembre de $1843^{\prime \prime}$.

73. P. Barbadillo Delgado (1942), pp. 769-773.

74. Sería muy divertido seguir la pista a todos aquellos que han escrito sobre Andalucía. Veríamos como lo escrito por unos pocos pioneros es copiado sistemáticamente por todos los que le han seguido con la particularidad de que todos agregan de su imaginación particular algunas palabras, frase sueltas, dejadas caer con aparente ingenuidad, pero que sumadas unas con otras, año tras años, deforman de manera grave la realidad cuando sólo prueban el carácter racista o reaccionario de algunas estas "vacas sagradas" utilizadas "a saco" por la más ingenua historiografía española. Tuve la oportunidad de comprobarlo (A. Cabral Chamorro, 1987), en otro contexto, para el caso de la historia social, y ahora lo vuelvo a constatar para el caso del Botánico. Veamos al respetado "viajero" R. Ford (1980, p. 175) dando cuenta del Motín de Aranjuez. en su versión sanluqueña: "El populacho se precipitó contra el (Jardín), mató a los animales, arrancó las plantas y echó a bajo los edificios... La venganza del español es oriental y nunca olvida o perdona; es ciego incluso a sus propios intereses, vengándose de las personas y de sus obras hasta cuando estas son de utilidad pública". Y es que, como ya señalara Sarrailh para los viajeros del siglo XVIII (1957, p. 222), muchos de aquellos peregrinos "son autores puramente ocasionales, cuya «documentación» suele estar plagiada de obras sin mérito alguno". 
rio $^{75}$. Sus primeras actividades las encaminó a poner en marcha el antiguo Botánico. Paralelamente, desde París y Madrid, Francisco Terán, Roxas y Lagasca iniciaron gestiones dirigidas al mismo fin ${ }^{76}$. En 1821, la Sociedad Económica sanluqueña en unión del Ayuntamiento, elevaron una exposición a la Diputación donde solicitaban la apertura y entrega del Jardín y los papeles de la antigua Sociedad. La Diputación ordenó al ayuntamiento su entrega sin daños a terceros ${ }^{77}$. Las gestiones cruzadas de unos y de otros dieron su fruto: el Gobierno solicitó información del acerca del estado del Jardín y por Real Orden de 30 de enero del mismo año mandó que se tomasen las medidas oportunas para ponerlo de nuevo en funcionamiento ${ }^{78}$. Por de pronto, las gestiones de la provincia marcharon en consonancia con las buenas intenciones de las Cortes que mediante el decreto de 29 de junio de 1822 ordenó que en todas las capitales de provincia se reservase una suerte de tierra para "jardín botánico y esperimentos de agricultura"79. Por Real Orden de 23 de enero, el Gobierno mandó a la Diputación que de acuerdo con la Sociedad de Sanlúcar fijasen los medios para dotar el Jardín con cien mil reales ${ }^{80}$. La Sociedad Económica sanluqueña procedió a realizar el oportuno presupuesto que corrió a cargo de Juan Francisco Terán: 19.320 reales para el mantenimiento y conservación del Jardín y 20.680 reales para la cátedra de agricultura. Los gastos serían cubierto mediante un arbitrio ${ }^{81}$. La Diputación falta de recursos propios y llena de dificultades para hacer cumplir a los pueblos de la provincia sus obligaciones físcales no autorizó los arbitrios ${ }^{82}$.

Con la vuelta de Fernando VII, el Jardín terminó por arruinarse. Posteriormente el Ayuntamiento de la ciudad lo cedió a los Duques de Montpesier ${ }^{83}$.

75. Archivo Histórico Provincial de Cádiz (AHPC), Gobierno Civil (GC), leg. 57, "Real Decreto para que se tomen las medidas que sean conducentes para que se establezca el Jardín de Aclimatación de Sanlúcar".

76. AJBM, División 1, 58, 3, 7, Carta de Francisco Terán a Simón de Roxas Clemente fechada en parís a 16 de diciembre de 1820 .

77. Archivo Histórico de la Diputación de Cádiz (AHDC), Libro de Actas de la Diputación (LAD), Acta de 25-I-182.

78. AHDC, $L A D$, Acta de 21-XII-1821 y AHPC, $G C$, leg. 56 y 57 , "Real Decreto para que se tomen las medidas que sean conducentes para que se establezca el Jardín de Aclimatación de Sanlúcar".

79. El Decreto de las Cortes de 29 de junio de 1822 en Bienes Nacionales. Desamortización. Leyes, reales decretos, reales órdenes, circulares e instrucciones sobre el particular, y reales disposiciones acerca del repartimiento de tierras, José María Guerrero, (1855), Cádiz, pp. 110-116.

80. AHPC, $G C$, leg. 61, "Real Orden sobre determinar la cantidad de 100.000 reales para la conservación del Jardín de Aclimatación".

81. AHDC, $L A D$, Acta de 17-III-1823.

82. Ibid. Acerca de la falta de recursos de los pueblos y de la Diputación y de sus permanentes agobios para cumplir las más mínimas tareas informa sobradamente el $L A D$, Actas de los años 1820-1823.

83. F. Guillamas y Galiano (1858), p. 213. 


\section{LAS REALIZACIONES DEL BOTÁNICO}

Respecto a las realizaciones prácticas según Barbadillo a el se le debe la aclimatación de distintas especies vegetales entre las que señalaba zulla (Hedysarum coronarium $)^{84}$. Sin duda, respecto a la zulla, se trata de un error de Barbadillo; esta leguminosa nace espontáneamente en los rastrojos de la provincia de Cádiz, en especial en las localidades de Tarifa, Jerez, Sanlúcar y Trebujena en cuyos "parajes se conoce desde tiempo inmemorial" ", después de las primeras lluvias otoñales, y será durante muchos años uno de los pilares de la alimentación del ganado en la campiña gaditana; de la zulla y de su papel hablaremos más adelante, por ahora baste lo apuntado. Según Godoy:

"En Sanlúcar prevalecían y prosperaban ya y se daban el árbol de la quina, y los de la canela, del cacao, del plátano, y del coco, con otras muchas plantas, árboles y arbustos del América y del Asia, huéspedes ya seguro de la España, que a vueltas de pocos años habría enriquecido más y más el mediodía de nuestras costas, y habrían tomado carta puebla entre nosotros" ${ }^{186}$.

Noticias más exactas y concretas nos la proporciona Simón de Rojas Clemente en una pequeña y preciosa memoria sobre la Producciones vegetales de Sanlúcar de Barrameda. Según Clemente al Jardín se le debe la introducción de mas de 40 especies planta desconocidas en la provincia y aún en Andalucía hasta aquellos momentos como son: el sauce, el algarrobo, la Sofora, el almez, el fresno, el chopo, el plátano, yerba de guinea y de Hungría, panizo, etc. En dos años de existencia el ayuntamiento de Sanlúcar llevó a cabo plantaciones de consideración y fueron expedidos más de 7.000 plantones de las mas diversa especies a Jerez, Cádiz, Sevilla, Chiclana y otras localidades y se realizaron exitosos ensayos con el algodón de Motril, barrilla, Zumaque, añil, Tabaco, Zahina blanca, arroz de secano, etc. ${ }^{87}$. Mucho de todo aquello se perdió en la memoria pero, de otro tanto, de las especies arbóreas, da buena cuenta, aún hoy, los jardines y paseos públicos de la provincia de gaditana.

Más difíciles de medir y valorar, pero no de menor importancia, fueron las relaciones intelectuales y humanas que un nutrido grupo de labradores, viticultores y exportadores de vino de la campiña establecieron con dos de los prohombre de la Botánica española del momento: Esteban Botelou y Simón de Roxas Clemente. Este aspecto, que consideramos esencial, baste por ahora con apuntarlo ya que de el me ocupo largamente en otro lugar.

84. P. Barbadillo Delgado (1942), p. 83.

85. "Del cultivo de la zulla", SAAP, 173, (1800), pp. 257-266.

86. M. Godoy, vol. II, pp. 143-144.

87. Simón de Roxas Clemente, Producciones vegetales de Sanlúcar de Barrameda (manuscrito), ARJBM, División I, 15, 2, 4. 


\section{BIBLIOGRAFÍA}

ACTAS DEL SIMPOSIUM CCL ANIVERSARIO del nacimiento de Josep Celestino Mutis, Diputación de Cádiz (1986), Cádiz.

AMOROS, F. (1804): Discurso que leyó el Sr. D. Francisco Amorós secretario de S.M. y oficial de la secretaria del despacho universal de la guerra, en la Junta que celebró la Sociedad económica de Sanlúcar de Barrameda la mañana del día 30 de noviembre del año de 1803 , con motivo de haberse recibido por Regidor de la misma ciudad el Excmo. Sr: Generalísimo Príncipe de la Paz, en cuyo obsequio casó este real Cuerpo seis huérfanas, y dotó diez y nueve. Se da a la luz por acuerdo de la misma Sociedad, con algunas notas añadidas posteriormente por su autor, Imprenta de la Casa de la Misericordia, Cádiz.

- (1814): Representación del Consejero de Estado D... a Fernando VII, quejándose de la persecución que experimenta su mujer... de parte del capitán general de Castilla la Nueva, y defendiendo la conducta que ha tenido Amorós en las convulsiones políticas de su patria, acompañada de documentos. París.

(1830): Manuel d'éducation physique, gymnástique et morel, Enciclopedia Roret, París, 2 vols.

ANES, G. (1969): "La Revolución Francesa y España. Algunos datos y documentos", Anes, G., Economía e "Ilustración" en la España del siglo XVIII, Ariel, Barcelona, pp. 139-198.

- (1989): "España y la Revolución Francesa”, Revolución y contrarrevolución e independencia. La revolución Francesa, España y Amêrica, Turner, Madrid, pp. 17-39.

ANTON, B. (1865): Diccionario de biblingrafía agronómica de toda clase de escritos relacionados con la agricultura seguida de un índice de autores y traductres con algunos auntes biográficos, Madrid, M. Rivadeneyra.

ARTOLA, M. (1976): Los afrancesados, Ediciones Turner, Madrid.

AYMES, J.R. (1989): “España y la Revolución Francesa: ensayo de bibliografía crítica”, Aymes, J.R. (ed.), España y la Revolución Francesa, Crítica, Barcelona, pp. 3-68.

BARBADILLO DELGADO, P. (1942): Historia de la citudad de Sanlúcar de Barrameda, Cerón y Librería Cervantes, Cádiz.

BARRAS DE ARAGÓN, F. de las (1911): "Noticias del Jardín Botánico de Sanlúcar y sobre Domingo Badía", Boletín de la Real Sociedad Española de Historia Natural, vol. 9, pp. 142144.

BARREIRO, A.J. (1992): El Museo Nacional de Ciencias Naturales (1771-1935), ed. a cargo de Pedro M. Sánchez Moreno, Doce Calles y Museo Nacional de Ciencias Naturales, Madrid.

BIENES NACIONALES. Desamortización. Leyes, reales decretos, reales ordenes, circulares $e$ instrucciones sobre el particular, y reales disposiciones acerca del repartimiento de tierras, José María Guerrero, (1855), Cádiz.

CABRAL CHAMORRO, A. (1987): "Un estudio sobre la composición social y arraigo del anarquismo en Jerez de la Frontera, 1869-1923”, Estudios de Historia Social, 42/43, pp. 209235.

CASADO ARBONIES, M. (1991): "Bajo el signo de la militarización: las primeras expediciones científicas ilustradas a América (1773-1761)", La Ciencia Ilustrada en Ultramar: Actas de las I Jornadas sobre "España y las expediciones científicas en América y Filipinas". Ediciones Doce Calles, Madrid, pp. 19-47.

CHASTENET, J: (1963): Godoy y la España de Goya, Planeta, Barcelona.

DEMERSON, P. de (1976): Sanlúcar de Barrameda en la corriente en la corriente de la Ilustración, Diputación Provincial de Cádiz, San Fernando. 
DOMERGUE, L. (1989): "Propaganda y contrapropaganda en España durante la Revolución francesa (1789-1795)”, Aymes, J.R. (ed.), España y la Revolución Francesa, Crítica, Barcelona, pp. 119-167.

DOMÍNGUEZ ORTIZ, A. (1989): "La Corona, el Gobierno y las instituciones ante el fenómeno revolucionario", E. Moral Sandoval (Coord.), España y la Revolución Francesa, Pablo Iglesias, Madrid, pp. 1-16.

DUHAMEL DE MONCEAU (1773-1774): Tratado del cuidado y aprovechamiento de los montes y bosques, corta, poda, beneficio y uso de sus maderas y leñas..., J. Ibarra, Madrid, 2 vols.

- (1805a): Compendio del tratado sobre siembras y plantios de árboles y su cultivo o medios de multiplicar y critar árboles; de plantarlos en espesillos y alamedas; de formar montes y bosques y restable los deterioros..., Imprenta Real, Madrid.

ELORZA, A. (1989): "El temido árbol de la libertad", en Aynes, J.R. (ed.), España y la Revolución Francesa, Crítica, Barcelona, pp. 69-117.

EQUIPO MADRID (1988): Carlos III, Madrid y la Ilustración, Siglo XXI, Madrid.

FERRER, D. (1961): Historia del Real Colegio de Cirugia de la Armada de Cádiz, Colegio Oficial de Médicos, Cádiz.

FONTANA, J. (1989): "Prólogo", Aymes, J.R., España y la Revolución Francesa, Crítica, Barcelona, pp. VII-XIV.

FORD, R. (1980): Manual para viajeros por Andalucía y lectores en casa, Turner, Madrid,

GARCÍA GARCÍA, T. (1962): "Contribución sanluqueña a la historia agrícola nacional", Archivo Hispalense, 36, pp. 105-111.

GARCÍA GONZÁLEZ, A.F. y RODRÍGUEZ GARCÍA, V: (1978): "Proyectos de Jardines botánicos para aclimatar plantas americanas en Andalucía: 1780-1800", Actas I Congreso Historia de Andalucía Diciembre 1976. Andalucía Moderna (Siglo XVIII), Monte de Piedad y Caja de Ahorros de Córdoba, Córdoba, vol. I, pp. 229-238.

GODOY, M. (1965): Memorias critica y apologéticas para la historia del reinado del señor $D$. Carlos IV de Borbón, BAE, vol, LXXXVIII, 2 vols. Madrid.

GONZÁLEZ, A.I. (1985): "El Jardín de la Paz", Cádiz e Iberoamérica, 3, pp. 31-34.

GUILLAMAS GALIANO, F. (1858): Historia de Sanlúcar de Barrameda, Imprenta de Sordomudos y Ciegos, Madrid.

HERR, R. (1979): España y la revolución del siglo XVIII, Aguilar, Madrid.

JURETSCHKE, H: (1962): Los afrancesados en la guerra de la independencia, Rialp, Madrid.

LAFUENTE, A. (1985): "Militarización de las actividades científicas en la España Ilustrada", La Ciencia Moderna y el Nuevo Mundo. Actas de la I reunión de Historia de la Ciencia y de la Técnica de los países ibéricos e iberoamericanos, CSIC y Sociedad Latinoamericana de Historia de las Ciencias y la tecnología, Madid, pp. 127-147.

— y PESET, J.L. (1988): "Las actividades e instituciones científicas en la España ilustrada", en Selles, M. Lafuente, A. y Peset, J.L. (comps.), Carlos III y Ia ciencia de la Ilustración, Alianza Editorial, Madrid, pp. 29-79.

LEGRAN, G. y LADEGAILLERIE, J. (1970): L'education physique au XIX e au XX siècle I. En France, A. Colin, París.

MADOL, H.R. (1987): Godoy. El primer dictador de nuestro tiempo, Alianza Editorial, Madrid.

MANANTEAU, L. et alii (1991): Los pueblos de la Provincia de Cádiz. Sanlúcar de Barrameda, Diputación Provincial de Cádiz, Cádiz, Vol. II.

MERCADER RIBA, J. (1965): Domenech Badía, "Alí.Bey". Un aventurer catalá al servicio de Godoy y de José 1, Rafael Dalmau, Barcelona. 
- (1983): José Bonaparte Rey de España (1808-1813). Estructura del Estado español bonapartista, CSIC, Madrid.

MESTRE, A. (1976): Despotismo e llustración en España, Ariel, Barcelona.

MOREL FATIO, A. (1924-1925): "D. Francisco Amorós, marquis de Sotelo, fondateur de la gymnatique en France", BHi, vol. XXVI, pp. 209 y ss. y vol. XXVII, pp. 37 y ss.

ORTEGA, C. (1805): "Prólogo" a la obra de Duhamel de Monceau, Compendio del tratado sobre siembras y plantios de árboles y su cultivo o medios de multiplicar y criar árboles; de plantarlos en espesillos y alamedas; de formar montes y bosques y restable los deterioros..., Imprenta Real, Madrid..., pp. I-XII,

PIERNAVIEJA, M. (1979-1980): "Francisco Amorós, el primer Gimnasiarca español", Gimnástica III. Lecturas complementaria, Instituto Nacional de Educación Física, Madrid.

PUERTO SARMIENTO, F.J. (1988): La ilusión quebrada. Botánica, sanidad y política cientifica en la España ilustrada, Serbal/CSIC, Barcelona-Madrid.

REYES, de los, E. (1961): Amorós. Adelantado de la Gimnasia moderna. Su vida, su sistema, Comité Olímpico español, Madrid.

ROURA i AULINAS, L. (1990): "La Revolución Francesa: una mirada al Bicentenario", Historia Social, 8, pp. 135-157.

ROXAS CLEMENTE, S. de (1807): Ensayo sobre las variedades de la vid que vegetan en Andalucia, con un índice etimológico y tres listas de plantus en que se caracterizan varias especies nuevas, Villalpando, Madrid.

SARRAILH, J. (1957): La España ilustrada en la segunda mitad del siglo XVIII, México, Fondo de Cultura Económica.

SECO SERRANO, C. (1978a): Godoy: el hombre y el político, España-Calpe, Madrid.

- (1978b): "La época de Godoy", La Ilustración española. Clarooscuro de un siglo maldito, Historia 16, Madrid 1978, Extra VIII, pp. 87-104.

SELLES, M.A. (1988a): El Observatorio de Cádiz (1753-183I), Ministerio de Defensa. Instituto de Historia Naval, Madrid.

- (1978b): "La Academia y el Observatorio de Marina", Selles, M.A. Peset, J.L. y Lafuente, L., (comps.), Carlos III y la ciencia de la llustración, Alianza Editorial, pp. 173-186.

- (1991): "Instituciones científicas ilustradas de la Marina", La Ciencia Ilustrada en Ultramar. Actas de las I Jornadas sobre "España y las expediciones científicas en América y Filipinas". Ediciones Doce Calles, Madrid, pp. 97-105.

—, M.A. PESET, J.L. y LAFUENTE, L. (comps.), (1988c): Selles, M.A. Peset, J.L. y Lafuente, L. (comps.), Carlos III y la ciencia de la Ilustración, Alianza Editorial, pp. 173-186.

URTEAGA, L. (1987): La tierra esquilmada. Las ideas sobre la conservación de la naturaleza en la cultura española del siglo XVIII, Serbal/CSIC, Barcelona. 